\title{
Local-scale dispersal patterns and susceptibility to Dryocosmus kuriphilus in different Castanea species and hybrid clones: insights from a field trial
}

\author{
Fernando Castedo-Dorado ${ }^{1}$ (D) - Pedro Álvarez-Álvarez ${ }^{2}$ (iD) - Beatriz Cuenca Valera ${ }^{3}$. \\ María Josefa Lombardero ${ }^{4}$ (D)
}

Received: 24 April 2021 / Accepted: 6 November 2021 / Published online: 26 November 2021

(C) The Author(s) 2021

\begin{abstract}
The chestnut gall wasp Dryocosmus kuriphilus is a major insect pest affecting chestnut trees worldwide. Medium and long-term control of this pest can be improved by using resistant or less susceptible cultivars and hybrid clones. In addition, little is known about the local patterns of dispersal of the pest. We obtained data from trees of 3 chestnut species and 27 hybrid clones in a field trial in NW Spain with the aim of evaluating the susceptibility of the material to the gall wasp and identifying possible drivers of local spatial dispersal. In the first 3 years of the invasion by D. kuriphilus, the number of trees attacked and the number of galls on each tree were spatially clustered. Tree height significantly predicted both variables, suggesting that gall wasps may use visual cues to locate suitable host trees, at least in the early stage of invasion. Assessment of the susceptibility of hybrid clones/pure species must take concurrent indicators of infestation levels into account. We suggest the use of indices involving galls on shoots because these enable good assessment of the damage to chestnut trees. The study findings add to existing knowledge on the susceptibility of hybrid chestnut clones. We report, for the first time, two hybrid clones resistant to the pest and one hybrid clone which exhibited consistently low values for all of the indicators of infestation level. The results have important implications regarding selection of plant material for use in afforestation in Spain, where the current high rate of chestnut planting is expected to continue.
\end{abstract}

Keywords Chestnut trees · Hybrid clones - Asian chestnut gall wasp · Level of infestation · Local dispersal

\section{Introduction}

The European chestnut (Castanea sativa Mill.) is a hardwood species of considerable agroeconomic and strategic importance in NW Spain. This species provides several environmental functions, as well as economic (firewood, biomass, timber and nut production) and

Fernando Castedo-Dorado fcasd@unileon.es

Extended author information available on the last page of the article 
socio-cultural benefits. Framing these contributions as ecosystem services enables ecosystems to be linked to human welfare, ecological value and biodiversity and acknowledges the important role of these systems in rural development and the preservation of traditional landscapes and culture.

This species has been threatened by social factors, economic changes and two major introduced pathogens: Phytophthora cinnamomi Rands and Cryphonectria parasitica (Murril) Barr. The first of these, P. cinnamomi, causes ink disease, which usually leads to death of the affected trees. The widespread damage to $C$. sativa populations in NW Spain led to the initiation of a programme of hybridization between European chestnut and two Asiatic chestnut species (Castanea crenata Siebold \& Zucc and Castanea mollissima Blume) aimed at breeding local cultivars harbouring the resistance genes of the Asiatic species (Fernández-López 2011). Clonal forestry has been promoted with this hybrid material, with the main objectives being wood production and production of rootstocks for grafting with traditional varieties.

The Asian chestnut gall wasp (Dryocosmus kuriphilus Yasumatsu; Hymenoptera: Cynipidae) is the main insect pest that affects trees of the genus Castanea. It is a widespread invasive species that has become of concern in many countries, including Spain. In Galicia (NW Spain), D. kuriphilus was first reported in 2014 (Pérez-Otero and Mansilla 2014), and it is now present throughout the region (Gil-Tapetado et al. 2020). The current distribution of the gall wasp includes all ecosystems where chestnut trees occur: isolated trees, orchards, wild populations, coppices and hybrid clonal plantations. Infestation by the gall wasp can reduce nut production by up to $80 \%$ (Battisti et al. 2014) and can also reduce timber production (Marcolin et al. 2021) and the chestnut component of honey (Gehring et al. 2018a).

The existence of cultivars or varieties of chestnut that are resistant to D. kuriphilus was first reported in Japan, by Shiraga (1948). Several other authors subsequently reported that the level of infestation on $C$. sativa orchards mainly depends on the cultivar used (Panzavolta et al. 2012; Sartor et al. 2015; Pérez-Otero et al. 2017; Míguez-Soto et al. 2018). To date, studies that have focused on the comparative susceptibility of hybrid clones to the gall wasp are scarce (Sartor et al. 2015; Míguez-Soto et al. 2018). Both of the aforementioned studies reported a wide range of variability among clones in regard to the level of infestation by $D$. kuriphilus, suggesting a clear genotype-dependent variation in susceptibility. However, in some trials in both studies, the assessment was carried out inside insect-proof screened houses and with a controlled number of gall wasps on the infested trees. In addition, only seedlings were used, and therefore the responses of older trees to the pest may not have been reflected (Kolb et al. 2016). Moreover, previous studies in Japan with $C$. crenata showed that a biotype of the insect was able to overcome the resistance of some selected genotypes (Murakami 2010; Dini et al. 2012). This highlights the importance of assessing a large number of hybrid clones for future use.

Susceptibility to the gall wasp is commonly assessed by secondary effects, i.e. by means of some measure of the level of infestation, usually the number of galls per bud or the ratio of attacked buds (e.g. Kotobuki et al. 1985; Sartor et al. 2009), although susceptibility can act at other levels such as the number of eggs laid in each bud (Anderson et al. 1989; Nugnes et al. 2018). Moreover, in assessing susceptibility, the position where galls are formed on the plant organ has often been overlooked, although it is a key factor for assessing the effects of the pest (Kato and Hijii 1997; Maltoni et al. 2012).

At landscape scale, the natural dispersal of D. kuriphilus is assumed to be strongly affected by prevailing winds (EFSA 2010), although biotic factors such as host plant availability are also important (Gilioli et al. 2013). Nevertheless, little is known about the 
patterns of dispersal of the pest at the local scale (but see Graziosi and Rieske 2012). The aforementioned study (op. cit.) was carried in an area with a few sporadically distributed hosts occurring at a very low density, i.e. with a very different host distribution to that found in most areas of Europe where chestnut trees occur, including NW Spain.

The oviposition of cynipids and subsequent gall development can be sensitive to host attributes including genotype and size, among others (Stone et al. 2002). As in other galling insects, the gall wasps use host plant cues to detect and orient them to chestnut buds. Germinara et al. (2011) reported that D. kuriphilus responds to olfactory cues in the choice of host buds, although this was observed at spatial scales of less than one metre. In some galling insects, females prefer to oviposit on taller individuals (e.g. Cronin et al. 2001), and it has even been suggested that differences in bud size affect oviposition behaviour in D. kuriphilus (Kato and Hijii 1993). It can therefore be hypothesized that visual cues may play a role in both oviposition selection by adult gall wasps and in the subsequent infestation level. Thus, both tree and bud size are potentially important features explaining these phenomena.

If genotype is a key factor in explaining host plant quality, local-scale spatial dispersion should be driven by the spatial location of certain genotypes (e.g. Anderson et al. 1989). In addition, neighbouring trees or tree attributes such as tree size may help in interpreting the spatial patterns of this dispersion. An existing field trial in which chestnut hybrid clones with potentially different levels of susceptibility to gall wasp occurred in the same area provided an opportunity to examine the dispersal patterns.

In this study, we obtained data from trees of 3 chestnut species and 27 hybrid clones growing in a field trial with the aim of evaluating (1) the susceptibility to gall wasp as indicated by different infestation indicators and (2) the possible drivers of local-scale spatial patterns of gall wasp dispersal.

\section{Material and methods}

\section{Field trial and experimental design}

The field trial is located in San Xoan de Lagostelle (Galicia, NW Spain), at an elevation of $505 \mathrm{~m}$ a.s.1. (ETRS89/ UTM zone 29T coordinates: 587,161 mE, 4,786,989 mN). The trial was established in the spring of 2004 to test certain traits of interest in the Galician breeding programme for hybrid chestnut clones. The traits considered include vigour, apical dominance, stem straightness and resistance to ink disease. Shrubs were cleared and subsoiling was carried out before planting, and a plant spacing of $3.8 \times 3.8 \mathrm{~m}$ was used. In total, trees of 3 chestnut species (C. sativa, C. crenata, C. mollissima) and 31 hybrid chestnut clones were planted. In four of the clones ('88', '125', '392' and '90044'), some of the variables were not measured because the high density of tall shrubs prevented access to several trees, and the data on these clones were therefore excluded from further analysis. A total of 27 clones were finally considered (Table 1). Thirteen of these clones are approved as belonging to qualified or tested categories of forest reproductive material in Spain (MITECO 2021), and they can therefore be produced for commercial use in afforestation according to Directive 1999/105/EC (European Council 1999). Moreover, 5 of these 13 clones are approved as commercial rootstocks for grafting $C$. sativa varieties in Spain (BOE 2020). 
Table 1 Data on the approved use as forest reproductive material and as rootstock of the 27 hybrid chestnut clones and 3 pure chestnut species considered in the study

\begin{tabular}{|c|c|c|c|c|}
\hline Hybrid clone/pure species & $\begin{array}{l}\text { Approved as forest } \\
\text { reproductive material }\end{array}$ & $\begin{array}{l}\text { Forest reproductive } \\
\text { material category }\end{array}$ & $\begin{array}{l}\text { Approved as } \\
\text { rootstock }\end{array}$ & $\begin{array}{l}h(\mathrm{~m}) \\
\text { Mean (min-max) }\end{array}$ \\
\hline '2' & No & - & No & $4.8(2.6-8.2)$ \\
\hline ' 3 ' & Yes & Qualified & No & $7.3(5.0-9.3)$ \\
\hline '19' & Yes & Tested & No & $5.2(2.5-7.1)$ \\
\hline '89' & Yes & Qualified & No & $6.6(3.2-8.8)$ \\
\hline ‘110’ & No & - & No & $8.2(6.0-9.8)$ \\
\hline '111' & Yes & Tested & Yes & $6.6(4.1-9.1)$ \\
\hline ‘324’ & Yes & Qualified & No & $7.0(3.7-9.5)$ \\
\hline ‘334’ & No & - & No & $8.3(4.8-10.1)$ \\
\hline '431’' & Yes & Tested & No & $5.3(3.6-6.8)$ \\
\hline 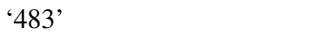 & No & - & No & $6.8(4.8-9.5)$ \\
\hline '502’ & No & - & No & $7.9(6.0-10.0)$ \\
\hline '525' & No & - & No & $6.3(4.2-7.6)$ \\
\hline ‘ $1483 ’$ & Yes & Qualified & Yes & $5.3(3.2-7.0)$ \\
\hline '2671’ & Yes & Qualified & Yes & $7.6(3.0-10.1)$ \\
\hline '6351' & No & - & No & $5.6(3.7-7.5)$ \\
\hline ‘7509’ & No & - & No & $8.1(3.6-10.3)$ \\
\hline ‘7521’ & Yes & Tested & Yes & $7.8(4.0-9.5)$ \\
\hline ‘7801' & No & - & No & $9.8(8.6-10.9)$ \\
\hline ‘7810’ & Yes & Qualified & Yes & $6.9(3.9-8.9)$ \\
\hline ‘7811’ & No & - & No & $9.4(7.6-10.5)$ \\
\hline ‘7817’ & No & - & No & $7.6(4.1-10.4)$ \\
\hline '9187' & No & - & No & $6.4(5.0-9.1)$ \\
\hline '9514’ & No & - & No & $9.7(7.8-11.0)$ \\
\hline '90025' & Yes & Tested & No & $5.4(2.3-7.1)$ \\
\hline 'CA-15' & Yes & Tested & No & $8.6(4.0-10.2)$ \\
\hline 'HS' & Yes & Tested & No & $6.9(2.1-9.9)$ \\
\hline 'T-13' & No & - & No & $7.5(6.2-9.0)$ \\
\hline C. crenata & No & - & - & $6.7(1.8-9.3)$ \\
\hline C. mollissima & No & - & - & $3.2(1.4-5.6)$ \\
\hline C. sativa & Yes & Source-identified & - & $4.8(2.7-6.4)$ \\
\hline
\end{tabular}

The mean, minimum and maximum heights of trees of each hybrid clone/pure species are also included (Min. and Max. in brackets)

Clone 'CA-15' originates from a breeding programme conducted in France by the INRA (Salesses et al. 1993) and is also called 'Marigoule'. The majority of the clones (26) are hybrids obtained by crossing $C$. crenata and C. sativa, and one clone ('7521') was produced by crossing $C$. mollissima and $C$. sativa. Trees of the three species used in the hybridization process ( $C$. crenata, $C$. mollissima and $C$. sativa), grown from seed, were also included in the trial.

The experimental design was a randomized complete block design for the hybrid clone/ pure species level. Six replicate blocks were established, although only four adjacent replicates were considered in the present study (A to D in Fig. 1). We selected only the four 


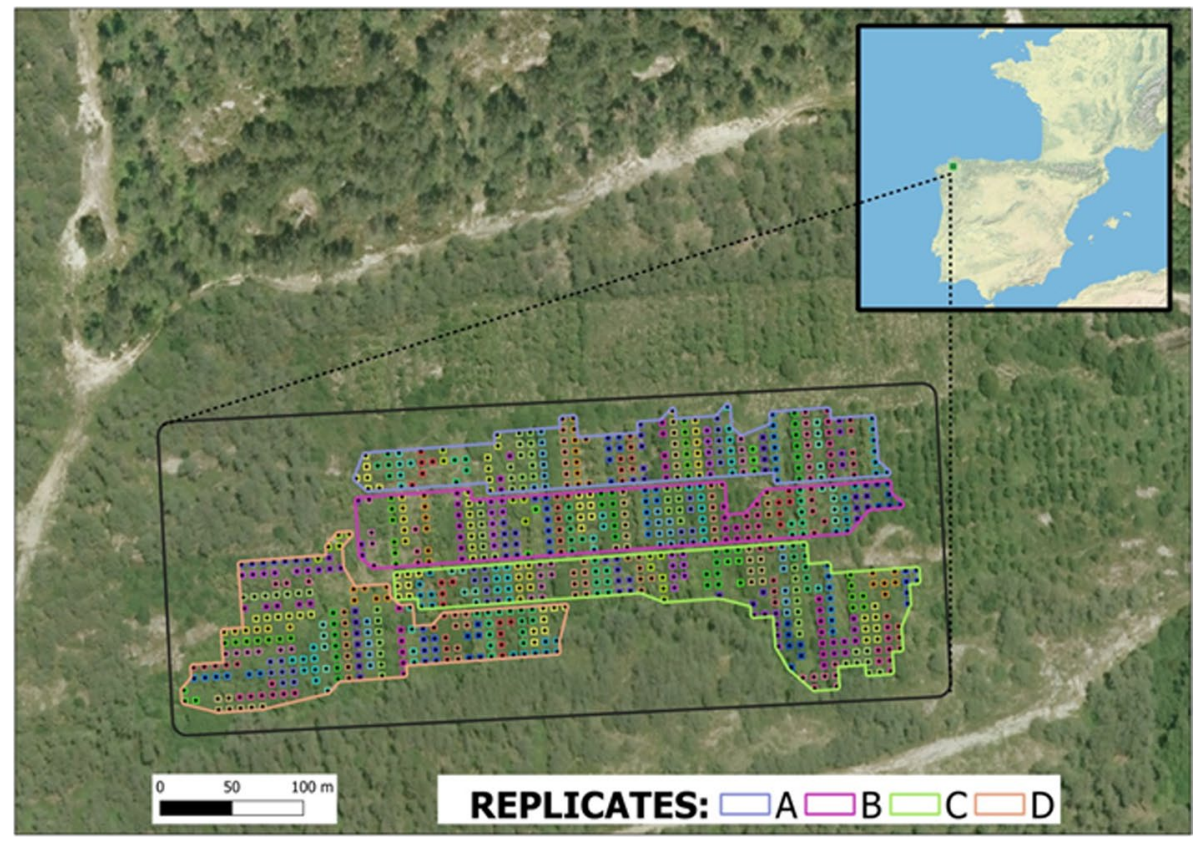

Fig. 1 Location of the field trial in Galicia (NW of Spain), and location of the four replicate blocks within the trial

replicate blocks corresponding to a north-facing slope to prevent including gradient of environmental variation. Seven plants of each hybrid clone or pure species were initially planted in each replicate. Some mortality occurred after planting and therefore seven plants were not available for some hybrid clones/pure species. A total of 834 trees were finally evaluated.

The pest is assumed to have arrived to the field trial in the summer of 2015, as fresh galls were first observed in the 2016 growing season.

Plants of most of the hybrid clones were propagated by the layering technique and only some were generated from cuttings. Layered ramets were supplied by the San Breixo Nursery (property of the regional Forestry Administration). Rooted cuttings were supplied by the Maceda nursery (belonging to TRAGSA, a Spanish agricultural transformation company), which purchased certified plants of chestnut hybrid clones from CIF Lourizán in 2000 to establish a mother plant field. Layered ramets and rooted cuttings were 1 year old at establishment. Seedlings of the three pure chestnut tree species were grown from seed and were purchased from Sandeman Seeds, UK, as ornamental plant lots.

\section{Field and laboratory sampling}

We measured the following traits in the 27 hybrid clones and 3 pure species: diameter at breast height, total height $(h)$ and number of galls in each tree in the field trial. The first two traits were assessed in March 2018, whereas the number of galls was evaluated in July of each of the 3 years of the study (2016, 2017 and 2018). Diameter at breast height was 
measured with a caliper and total tree height with a digital hypsometer. In all trees visible galls were counted by the same observer, with the aid of binoculars.

In September 2019, we randomly selected 10 trees per clone within the trial, and we cut two branches from the upper region of the crowns in each tree. In each branch, we located and examined the shoot that had grown in the previous growing season (2018). Along the length of the old shoot, we counted both the number of newly developed buds in the current (2019) growing season and the number of galls in these buds. When a gall was present on any organ on the current-year developed bud, it was considered infested, and the gall was further classified as present on a shoot or a leaf (Maltoni et al. 2012). We used these data to calculate two commonly used susceptibility indices for each tree: (1) the ratio between the number of galls and the number of buds in 2019 (GpB; e.g. Sartor et al. 2009, 2015); and (2) the ratio between the number of attacked buds (i.e. buds with the presence of galls) and the total number of buds (AB; Kotobuki et al. 1985). In addition, we considered two susceptibility indices that focus on assessing the damage resulting from D. kuriphilus attack: (1) the ratio between the number of galls on shoots and the number of buds (GspB); and (2) the ratio between the number of galls on shoots and the total number of galls, expressed as a percentage (pGs).

At the end of August 2020, we randomly chose three trees per clone/ pure species, and we randomly selected and cut two terminal twigs from these. In the laboratory, we dissected the first three buds per twig under a stereomicroscope. We counted the number of eggs laid in each bud and we measured the diameter of the buds in two perpendicular directions with a digital calliper $( \pm 0.01 \mathrm{~mm})$.

\section{Statistical analysis}

We used different types of data analysis depending on the outcome data: continuous, discrete (counts) and dichotomous. For continuous variables (susceptibility indices), we aimed to identify any significant differences between hybrid clones/pure species. As tree size may explain some of the observed variability, tree height was included as a covariable. Before carrying out analysis of covariance (ANCOVA), we first examined the underlying assumptions of normality and homogeneity of variance by using respectively the Shapiro-Wilk and Levene's tests. When the results of these tests indicated non-compliance with the assumptions, appropriate data transformation was carried out. When the ANCOVA revealed significant differences between factors $(\alpha=0.05)$, Tukey's HSD post-hoc test was used to identify different groups of hybrid clones/pure species.

Generalized linear models (GLM) were used to analyse count variables. To determine the existence of any significant differences among hybrid clones/pure species in relation to the number of eggs laid per bud, a GLM was performed using hybrid clone/pure species as the main factor and the average bud diameter and tree height as covariates. As the dependent variable is zero-inflated (i.e. it possesses an 'excess' of zero counts) and over-dispersed (i.e. the conditional variance is greater than the conditional mean), a zero-inflated negative binomial model was used. In order to analyze differences among hybrid clones/pure species in relation to the number of buds per shoot, a Poisson regression model was used considering hybrid clone/pure species as the main factor and tree height as a covariate. In both types of analysis, when the clone/pure species was found to be a significant factor, pairwise comparisons of estimated marginal mean with Bonferroni adjustment were performed with the emmeans package in R ( $R$ Core Team 2020). 
We used Global Moran's I for statistical testing of global clustering of both attacked trees and the number of galls per tree across the field trial. This analysis was performed with ArcGIS v 10.4.1 for Desktop with the Spatial Autocorrelation tool (ESRI 2015) for each of the 3 years of the study. When, as expected, these variables were not spatially distributed at random, feasible causes of this performance were examined by modelling both the presence of attacked trees and the number of galls per tree.

We modelled the presence of attacked trees in each year by using a binary logistic regression model (GLM) with a dichotomous response variable $(0=$ tree not attacked; $1=$ tree attacked) and considering the hybrid clone/pure species, replicate and tree height as potential regressors. For each year, we considered only the trees belonging to hybrid clones/pure species in which at least one tree with galls was observed in that growing season. To assess the discriminatory power of the model, we used the area under the receiver operating characteristic curve (AUC), where a value of 0.5 indicated no discrimination, 0.6-0.8 indicated acceptable discrimination and 0.8-0.9 indicated excellent discrimination (Hosmer and Lemeshow 2000).

We modelled the number of galls per tree in each year using the replicate and the hybrid clone/pure species as main factors and tree height and the number of galls in the previous year (in 2017 and 2018) as covariates in the GLM. Poisson regression models or negative binomial regression models were used, depending on the relative value of the variance to the mean after accounting for the effect of the predictors. If the variance was larger than assumed in the model (overdispersion), a negative binomial regression model was used; otherwise, a Poisson regression model was used.

For all of the GLMs, the significant overall effect of categorical variables (clone/species and replicate) was determined by a likelihood ratio test of two models, one with and one without the categorical variables. Tree height was included as a covariate in all the GLMs, and as it was only measured in 2018, these values were used for modelling variables measured in 2018 as well as in 2019 and 2020.

Furthermore, data on galls on trees in the 2016 and 2017 growing seasons were used to analyze whether, in 2017, (1) the adults of the gall wasp showed a preference to spread to trees of the same hybrid clone/pure species that it had attacked in 2016 and (2) the number of galls per tree was related to the fact that the neighbouring tree was of the same hybrid clone/pure species as that initially attacked. We only carried out this analysis for the period 2016-2017, which corresponded with the beginning of the invasion and therefore the spread was able to be traced without considerable overlapping. For the 30 trees initially attacked in 2016, we identified the 4 closest neighbouring trees (above, below, right, left), and we subsequently investigated whether the proportion of attacked trees in the following year (2017) differed significantly depending on whether the neighbouring trees were of the same hybrid clone/pure species as the trees initially attacked. Fisher's exact test was used to test the null independence of rows and columns in the contingency table. Negative binomial or Poisson models were used to model the number of galls per tree in 2017, with tree height and the number of galls per tree in 2016 considered continuous variables, and replicates and the neighbouring trees of the same clone/species as the tree initially attacked considered main factors.

All analyses were carried out with R statistical software (R Core Team 2020). 

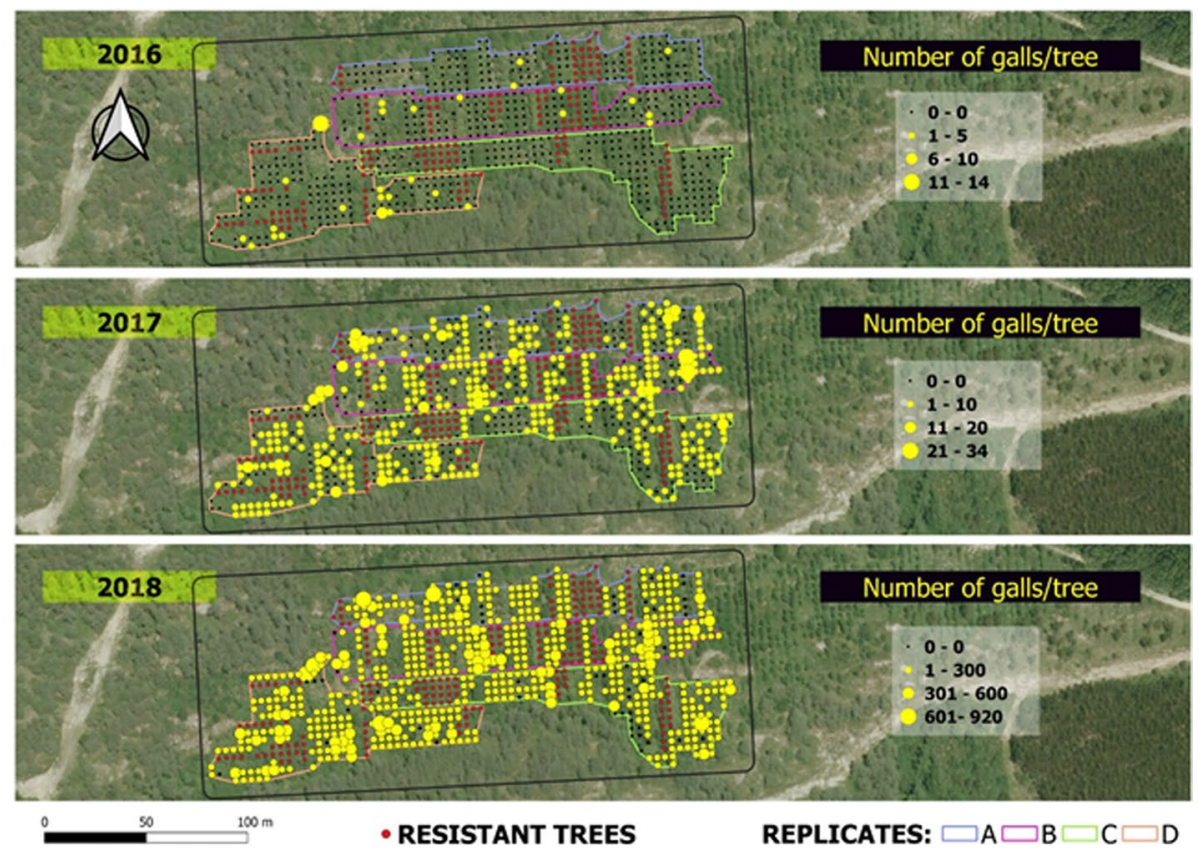

Fig. 2 Changes in the spatial distribution of the infested trees and the number of galls per tree in the 3-year period considered. Resistant clones are represented by red dots

Table 2 Summary of global Moran's I test for the presence of infested trees and for the number of galls per tree

\begin{tabular}{|c|c|c|c|c|c|c|}
\hline \multirow[t]{2}{*}{ Year } & \multicolumn{3}{|c|}{ Attacked trees } & \multicolumn{3}{|c|}{ Number of galls/tree } \\
\hline & Moran's I & $z$-score & $p$ value & Moran's I & $z$-score & $p$ value \\
\hline 2016 & 0.101 & 4.589 & $<0.0001$ & 0.014 & 0.774 & 0.439 \\
\hline 2017 & 0.206 & 9.125 & $<0.0001$ & 0.216 & 10.043 & $<0.0001$ \\
\hline 2018 & 0.349 & 15.487 & $<0.0001$ & 0.299 & 13.315 & $<0.0001$ \\
\hline
\end{tabular}

\section{Results}

The changes in the spatial distribution of the attacked trees for the 3 year-period considered are shown in Fig. 2, in which the size of the points is proportional to the number of galls per tree. In 2016 most of the attacked trees were in replicate D, and to a lesser extent, in replicate $\mathrm{A}$ and $\mathrm{B}$. No trees in replicate $\mathrm{C}$ were attacked at that time. In the following years the attacked trees were distributed throughout all four replicates.

Global Moran's I values and the associated $z$-score and $p$ values indicated that the attacked trees were not randomly spatially distributed in any of the 3 years considered. The same clustered pattern was observed for the number of galls per tree, except in 2016 (Table 2).

In the first year when galls were present (2016), only trees of 10 of the hybrid clones ('19', '111', '7509', '7801', '7811', '7817', '9514', '7521', 'CA-15' and 'HS') and C. sativa were attacked. In 2017, trees of all hybrid clones that were finally not resistant (all except clones '3', '89', '110', '324', '334' and '90025', see below) and of C. sativa and C. crenata 
were attacked. Galls were finally observed on C. mollissima trees in 2018. In 2016, 2017 and 2018, respectively 30, 384 and 607 of the 834 trees included in the trial were attacked. In 2018,48 trees of the hybrid clones that were attacked by the pest still had no galls.

For the 3 years considered, logistic regression models showed a positive relationship between tree height $(h)$ and the probability of a tree being attacked by the pest. According to the likelihood ratio test, the effects of both the clone/species and the replicate were significant, except in the first and third year of the invasion, respectively. The AUC values were higher than 0.73 for all 3 years, with the models showing an adequate capacity to discriminate between attacked and non-attacked trees (Table 3).

The results of a Poisson regression model (for the year 2016) and negative binomial models (for years 2017 and 2018) also showed a positive relationship between tree height (h) and the number of galls per tree. For 2017 and 2018, the number of galls per tree in the previous year was also significant and had a positive effect. According to the likelihood ratio test, the effects of both hybrid clone/pure species and replicate were significant, except for the replicate in the first year of invasion (Table 4).

The ratio of neighbouring trees attacked in 2017 of the same hybrid clone/pure species as that initially attacked in 2016 was 0.826 , whereas the ratio of attacked trees of a different hybrid clone/pure species from that initially attacked was 0.611. The value of the Fisher's exact test was 2.708 , and the associated $p$ value, 0.0610 , indicating that those proportions are not significantly different. This result shows that, at least in the initial dispersal phases, the gall wasp had no clear preference for spreading to trees belonging to the same hybrid clone/pure species that it had previously attacked.

Results of the negative binomial model used to explain the number of galls per tree in 2017 in the four neighbouring trees to that attacked in 2016 showed that neither tree height nor the replicate were significant, and only the number of galls per tree in the previous year had a positive and significant effect $(p$ value $=0.0333$ ). Interestingly, the fact that the neighbouring tree was of the same hybrid clone/pure species as that initially attacked was not significant (Table 5).

In 2018, the level of infestation by $D$. kuriphilus largely depended on the genotype. No galls were found in hybrid clones ' 3 ', '89', '110', '324', '334' and '90025' in the surveys carried out in 2016, 2017 and 2018, and therefore these clones were assumed to be resistant. Galls were found on $C$. sativa trees in all 3 years of the study, whereas

Table 3 Results of the logistic models fitted to explain the presence of infested trees in each year

\begin{tabular}{lllllllll}
\hline Year & Variable & Estimate & SE & z-value & $\operatorname{Pr}>(|\mathrm{z}|)$ & Deviance & $\operatorname{Pr}\left(>\chi^{2}\right)$ & AUC \\
\hline 2016 & $h$ & 0.548 & 0.212 & 1.909 & 0.0425 & - & - & 0.737 \\
& Replicate & - & - & - & - & -57.53 & 0.0128 & \\
& Clone/species & - & - & - & - & -43.98 & 0.472 & 0.754 \\
2017 & $h$ & 0.199 & 0.0934 & 2.127 & 0.0335 & - & - & \\
& Replicate & - & - & - & - & -169.4 & $<0.0001$ & \\
& Clone/species & - & - & - & - & -244.3 & $<0.0001$ & 0.834 \\
2018 & $h$ & 0.290 & 0.1132 & 1.801 & 0.0436 & - & - & \\
& Replicate & - & - & - & - & -78.25 & 0.346 & \\
& Clone/species & - & - & - & - & -191.6 & $<0.0001$ & \\
\hline
\end{tabular}

For main factors "replicate" and "hybrid clone/pure species", the results of the likelihood ratio test for checking the overall effect are included 
Table 4 Parameter estimates, standard errors, and $p$ values for Poisson (year 2016) and negative binomial models (years 2017 and 2018) explaining the number of galls per tree in each year

\begin{tabular}{lllllll}
\hline Year & Variable & Estimate & SE & $p$ value & $\chi^{2}$ & $\operatorname{Pr}\left(>\chi^{2}\right)$ \\
\hline 2016 & $h$ & 0.423 & 0.168 & 0.0118 & - & - \\
& Clone/species & - & - & - & 43.798 & $<0.0001$ \\
& Replicate & - & - & - & 2.549 & 0.110 \\
2017 & $h$ & 0.0572 & 0.0203 & 0.0394 & - & - \\
& No. of galls in 2016 & 0.0739 & 0.0302 & 0.0143 & - & - \\
& Clone/species & - & - & - & 62.475 & $<0.0001$ \\
& Replicate & - & - & - & 16.822 & 0.0008 \\
& $h$ & 0.101 & 0.0248 & $<0.0001$ & - & - \\
& No. of galls in 2017 & 0.0342 & 0.00838 & $<0.0001$ & - & - \\
& Clone/species & - & - & - & 177.418 & $<0.0001$ \\
& Replicate & - & - & - & 39.503 & $<0.0001$ \\
\hline
\end{tabular}

For the main factors "replicate" and "hybrid clone/pure species", the results of the likelihood ratio test for checking the overall effect are included

Table 5 Parameter estimates, standard errors and $p$ values for the negative binomial model used to explain the number of galls per neighbouring tree in 2017

\begin{tabular}{llllll}
\hline Variable & Estimate & S.E & $p$ value & $\chi^{2}$ & $\operatorname{Pr}\left(>\chi^{2}\right)$ \\
\hline$h$ & 0.064 & 0.0355 & 0.0713 & - & - \\
No. of galls in 2016 & 0.182 & 0.0818 & 0.0333 & - & - \\
Replicate & - & - & - & 2.959 & 0.398 \\
Same clone/species & - & - & - & 1.678 & 0.195 \\
\hline
\end{tabular}

For the main factors "replicate" and "same hybrid clone/pure species" the results of the likelihood ratio test used to check their overall effect are included

galls were only identified on C. mollissima trees in 2018. In the 2018 survey, the level of infestation in the 24 non-resistant hybrid clones and the three Castanea species was very variable.

The ANCOVA results show that the effect of the hybrid clone/pure species was significant for the four infestation indicators $(p<0.0001)$. Tree height was also highly significant for all indicators $(p<0.0001)$, except the percentage of galls on shoots $\left(\mathrm{F}_{1,236}=5.228, p<0.0233\right)$. Post-hoc analysis identified between $3(\mathrm{pgS})$ and 9 (AB) different groups of hybrid clones/pure species depending on the infestation indicator. Nevertheless, there were no significant differences among the hybrid clones/pure species for most of the indices (Fig. 3).

The ranking of hybrid clones/pure species varied depending on the indicator used to assess the level of infestation, although the lowest values were consistently observed for hybrid clones '9187' and '431' and C. mollissima.

According to the zero-inflated negative binomial model, the factor clone/species significantly predicted the number of eggs laid per bud in the 2020. I growing season ( $p$ value $<0.0001$ ), whereas neither the bud diameter nor tree height were significant factors ( $p$ value $=0.246$ and 0.602 , respectively). Pairwise comparison only revealed 


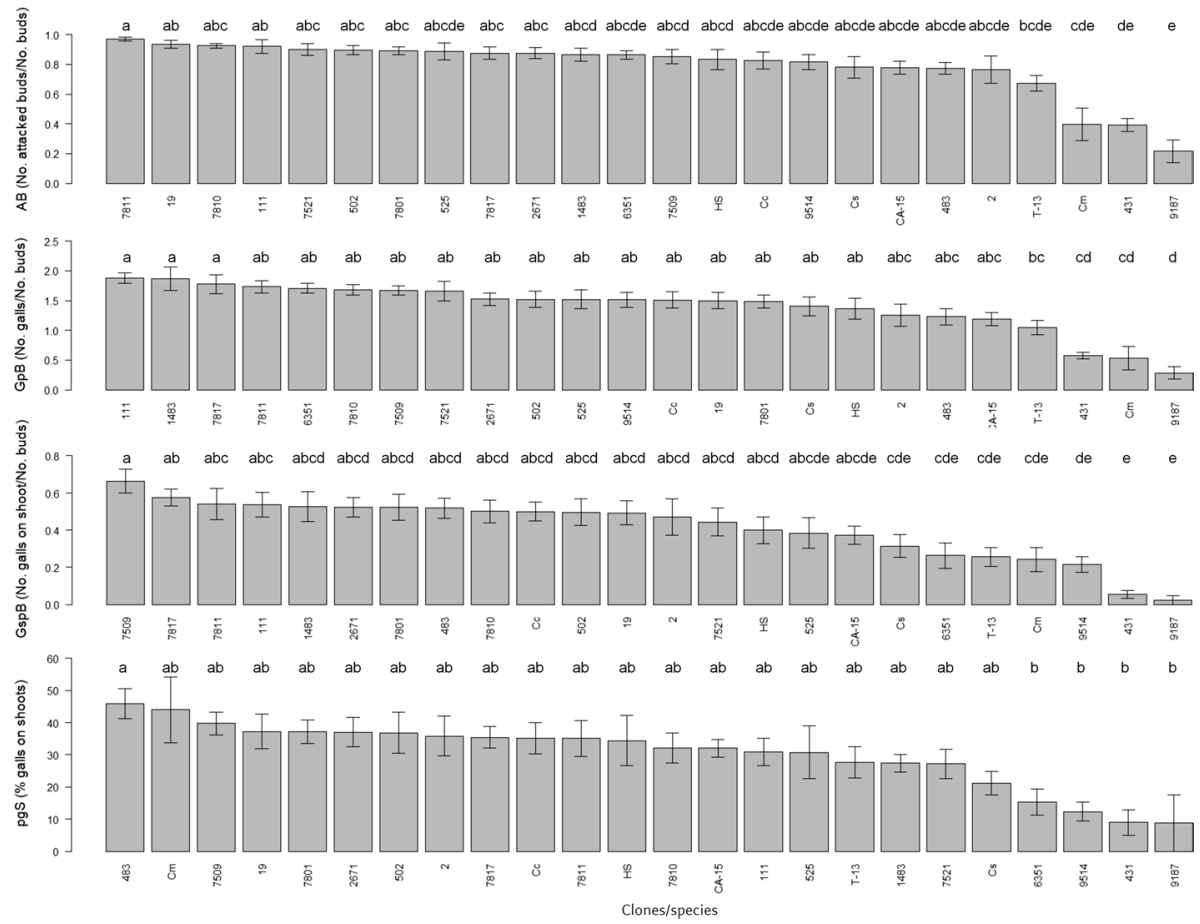

Fig. 3 Mean values $( \pm$ SE) of the four indicators used to assess the level of infestation in the 21 hybrid clones and 3 pure species with galls. Different letters indicate significant differences $(p<0.05)$ between hybrid clones/pure species. Normality assumptions do not hold for indicator $\mathrm{AB}$, but the bar chart was included for comparative purposes

significant differences between hybrid clone 1483 and hybrid clones 9187 and 7801 respectively (Fig. 4).

Neither the clone/species nor tree height were significant factors in explaining the number of buds per shoot, according to the fitted Poisson regression model $\left(\chi_{(1)}^{2}=1.2\right.$,

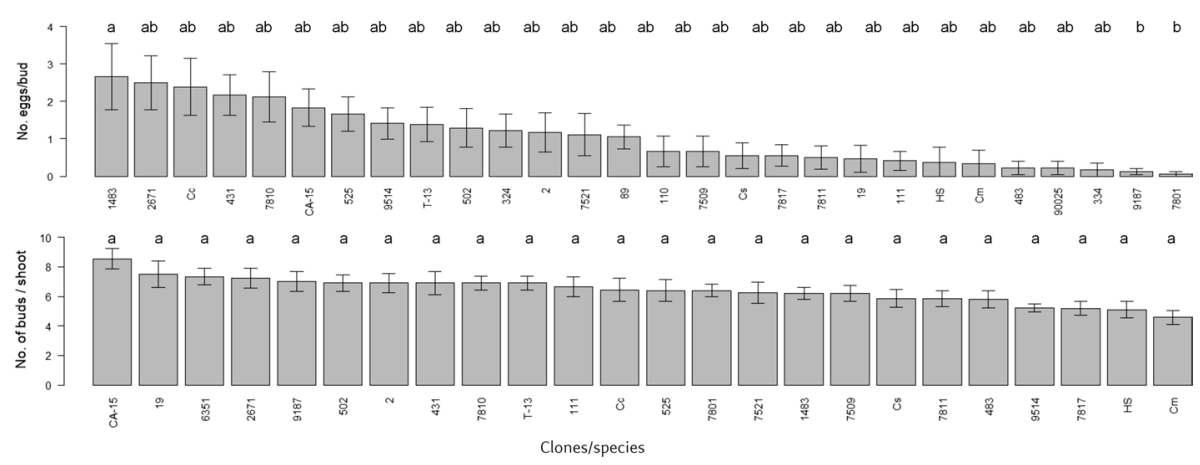

Fig. 4 Mean $( \pm S E)$ number of eggs laid per bud for the hybrid clones/pure species assessed (first row) and number of buds per shoot for the 24 hybrid clones/pure species with galls (second row). Different letters indicate significant differences $(p$ value $<0.05)$ between hybrid clones/pure species 
$\operatorname{Pr}\left(>\chi^{2}\right)=0.177 ;$ and $z$-value $=-0.380, \operatorname{Pr}(>|z|)=0.704$, respectively $)$. Therefore, only one group of hybrid clones was able to be defined according to this variable (Fig. 4).

\section{Discussion}

Analysis of the spatial dispersal of the gall wasp in the field trial suggested that, at least in the first few years after invasion, the gall wasp did not choose the attacked trees at random, but that the selection was affected by some variables. Hybrid clone/pure species was a significant factor explaining both the presence of attacked trees and the number of galls per tree in the whole field trial. Nevertheless, these results do not seem to be related to the infestation level observed in 2018 in the different clones/species. Thus, the trees first attacked in 2016 ('19', '111', '7509', '7801', '7811', '7817', '9514', '7521', 'CA-15', 'HS' and $C$. sativa) ranked intermediate according to the indicators used (the only exceptions were hybrid clones ' 111 ' and ' 7811 ' for $\mathrm{AB}$ and $\mathrm{GpB}$, which ranked high for these indices) (Fig. 3).

In addition to the hybrid clone/pure species, tree size had a significant, positive effect in explaining both the probability of a tree being attacked and the number of galls per tree. The positive effect of tree height on the existence of galls may indicate the preference of the gall wasp for the tallest trees within the hybrid clone/species, at least at the start of the invasion. It can be hypothesized that at the early stage of invasion, D. kuriphilus might use visual cues to locate suitable individual host trees. This type of behaviour has also been observed in other gall wasps (e.g. Cronin et al. 2001). The positive effect of tree height on the number of galls per tree was expected, as tree size will be correlated with the total number of available buds per tree for oviposition by gall wasps (Vieira da Costa 2011). These results support previous findings by Guyot et al. (2015), who observed that chestnut trees smaller than their neighbours in forest landscapes were less severely damaged by the invasive gall wasp.

The fact that the number of galls per tree in the previous year was a significant variable explaining the number of galls in subsequent years (in 2017 and 2018) may be due to recolonization of the same tree, at least when the gall wasp population density is low. At this stage of population dynamics, it is plausible that a substantial proportion of the adults will re-infect the same tree where they born, and the remaining population will colonize nearby trees.

Our findings also highlight the existence of different levels of susceptibility of hybrid clones and Castanea species in relation to gall formation. Six of the clones ('3', '89', '110', '324', 334' and '90025') were considered resistant, as no galls were found on these trees in any of the 3 year-period of study. Absence of galls was also reported by Míguez-Soto et al. (2018) in four of these clones in a year-long experiment (hybrid clones '110' and '334' were not evaluated in the previous study), providing additional support for the assumption of resistance. Galls were found on trees of all the remaining hybrid clones and each of the three species, although the level of infestation varied. A substantial level of variability was also be observed within hybrid clones and pure species.

Castanea sativa ranked intermediate between $C$. crenata and C. mollissima for the four infestation indicators, but lowest for the percentage of galls on shoots (pgS). In a recent study, Bombi et al. (2018) reported the existence of different levels of infestation in wild European populations of $C$. sativa, suggesting that the differences are due to specific features of individual trees within the populations. Until now, resistance has only been 
reported in a few cultivars of $C$. sativa (e.g. 'Pugnenga' and 'Savoye') (Sartor et al. 2015), although several less susceptible varieties have been described (e.g. Sartor et al. 2009, 2015; Pérez-Otero et al. 2017; Míguez-Soto et al. 2018; Nugnes et al. 2018; Bracalini et al. 2019).

Remarkably, in the field trial, $C$. crenata displayed the highest levels of infestation among the three pure species and according to the four indicators, except pgS. However, puzzlingly, existing resistant cultivars worldwide are mainly generated from $C$. crenata hybrids (Sartor et al. 2015), with $C$. crenata being the main source of resistance, as in the European breeding program focused on improving ink disease resistance (Pereira-Lorenzo et al. 2016). The reported difference in levels of susceptibility in $C$. crenata cultivars (e.g. Aino 1966; Park et al. 1981) may explain the contrasting findings in Euro-Japanese hybrids: no galls were observed in 'Bouche de Bétizac', while high levels of infestation were observed in 'Marsol' (Dini et al. 2012; Sartor et al. 2009, 2015).

We obtained mixed results regarding C. mollissima in our field trial. On the one hand, three indicators showed a low level of infestation, but the percentage of galls on shoots (pgS) was one of the highest observed. In addition, 6 of the 12 trees of this species included in the trial did not have galls 3 years after invasion (in 2018 survey). On the other hand, the only hybrid clone ('7521, obtained by crossing $C$. mollissima and $C$. sativa) evaluated had one of the highest levels of infestation in the trial. This contrasting susceptibility may be due to the high intra-specific genetic diversity of C. mollissima (Huang et al. 1994; PereiraLorenzo et al. 2016), which is also reflected in the existence of some cultivars resistant to the pest (Ding et al. 2004; Geng et al. 2015).

Regarding most Euro-Japanese hybrid clones, our findings confirm the moderate level of infestation of the hybrid clone 'CA-15' ('Marigoule'), reported by Sartor et al. (2009, 2015) and Gençer and Mert (2019), and the high level of infestation in hybrid clones '111', '2671', '1483', '7521' and '7810', and the low-level infestation of hybrid clone '431', also reported by Míguez-Soto et al. (2018).

According to the four indicators, the level of infestation across the field trial was quite high in 2019, much higher than that observed by other authors for similar time from invasion (e.g. Sartor et al. 2009, 2015; Gehring et al. 2018b; Gil-Tapetado et al. 2021). The variations in hybrid clone/pure species rankings depend on the indicator used to assess the level of infestation, highlighting the importance of defining susceptibility in selecting the most suitable sampling design.

Most of the studies assessing gall wasp infestation levels are based on the number of galls found on tree branches or on the ratio of attacked buds, whereas reports that consider indices including the plant organ where galls are formed, such as GspB and pgS, are scarce (e.g. Míguez-Soto et al. 2018; Gençer and Mert 2019). The GspB and pgS indices can also be considered proxies for tree damage, because the presence of galls on shoots precludes stem elongation and green biomass formation, and galls therefore are responsible for the high proportion of dead shoots and the most significant reduction in leaf area (Kato and Hijii 1997; Maltoni et al. 2012; Gehring et al. 2018b, 2020). As a result, these indicators are recommended in order to improve assessment of the actual damage in chestnut trees.

Remarkably, in 2020 some wasp eggs were found in all the hybrid clones/pure species (irrespective of the level of infestation), although significant differences among the clone/ species in the number of eggs per bud were only found in three hybrid clones ('1483' vs. '9187' and '7801'). Two of the hybrid clones considered resistant ('90025' and '334') and one with a low level of infestation ('9187') occupied the final positions regarding egg density. Nevertheless, this trend did not hold true for hybrid clone '431', which had a low level of infestation, or for the remaining resistant hybrid clones, which ranked intermediate 
according to the number of eggs per bud (Fig. 3). In addition, the absence of any effect of bud diameter in oviposition density was not expected a priori, as some previous studies have shown that D. kuriphilus prefers to lay eggs in larger buds (Kato and Hijii 2001; Panzavolta et al. 2012). Our findings appear to indicate that visual cues for the gall wasps do not include bud size.

Overall, the results suggest that the observed differences in the level of infestation by $D$. kuriphilus in hybrid clones/pure species cannot be attributed to differences in the number of eggs deposited in the buds. Likewise, the differences also cannot be attributed to differences in the number of buds per shoot available for oviposition as non-significant differences among clones/species were observed for this variable (Fig. 4).

Our results are consistent with those obtained by Fukuda and Okudai (1951), who concluded that the oviposition selectiveness did not differ between resistant and susceptible varieties of chestnut in Japan. Nevertheless, our findings contradict those of Nugnes et al. (2018), who reported that female gall wasps lay significantly fewer eggs in buds of a relatively unsusceptible $C$. sativa ecotype than in wild, susceptible ecotypes. Although our results do not enable identification of the exact cause of resistance in hybrid clones '3', '89', '110', '324', '334' and '90025' and the presence of different levels of infestation among other clones and species, we speculate that this phenomenon may be due to differences in the rate of egg or larval mortality. The mortality is probably due to a hypersensitive reaction, i.e. induced resistance that can be detected in the area immediately adjacent to the site of attack and appears as necrotic spots (e.g. Fernandes 1990).

Establishment of new chestnut plantations is one of the main actions required to promote, conserve and recover traditional agroforestry systems in rural areas and also provides an excellent opportunity for preserving the high biodiversity (Rodríguez-Guitián et al. 2005; Guitián et al. 2012) and maintaining the associated cultural landscapes (Díaz-Varela et al. 2018). Within this framework, a programme of incentives for chestnut plantations has been implemented by the regional government of Galicia in recent years. As a result of this initiative, an area of between 1000 and 2000 ha is currently planted annually with chestnut trees in Galicia (DOG 2016-2021). Moreover, the main forest policy document of the region (the Galician Forest Plan, Plan Forestal de Galicia or PFG) is currently under review, and once approved will establish the main guidelines for the Galician forestry sector for the next 20 years (Xunta de Galicia 2018). Forecasts for this time horizon in the PFG establish an increase in the surface area for chestnut tree species from the current 46,500 to 71,500 ha. The current high rate of chestnut planting should be accompanied by appropriate selection of the plant material for use in afforestation, considering the existence of major forest health issues such as ink disease and gall wasp infestation.

More than 400,000 chestnut plants are currently produced annually in Galicia, and more than half of these are hybrid clones (Xunta de Galicia 2020). Most of these plants are used in new plantations in Galicia, although a significant proportion is distributed in nearby regions in NW Spain (El Bierzo, Asturias). Clonal forestry has often been adopted for chestnut plantations in NW Spain in recent years in order to achieve resistance to ink disease and also to generate certain productive traits. Thus, to date, 39 hybrid clones have been approved in Spain for use as forest reproductive material of tested and qualified category. Nevertheless, as with the recent invasion of D. kuriphilus, the susceptibility to the gall wasp is emerging as a new clonal feature that must be taken into account.

Release of the parasitoid Torymus sinensis carried out in previous years and future releases will reduce the damage caused by the wasp in the medium term (Avtzis et al. 2019; Nieves-Aldrey et al. 2019). Nevertheless, in areas where production of ecosystem services is economically important, combining direct and short-term control with $T$. sinensis and 
adequate selection of clonal material is recommended for medium and long-term impacts (EFSA 2010).

Hybrid clones can be used for plantations aimed at round wood production, chestnut fruit production and production of rootstock for grafting traditional chestnut varieties. Four of the hybrid clones found to be resistant (' 3 , '89', '324' and '90025') are currently commercially produced clones. The two additional hybrid clones identified as resistant ('110' and '334') have not yet been authorized as forest reproductive material, but are possible candidates for upcoming approval taking this trait into account. Hybrid clone '110' has been recommended as rootstock (Pereira-Lorenzo et al. 2012) and could also be valuable for nut production (Miranda Fontaiña and Fernández López 2008).

Hybrid clones '431' and '9187' are also remarkable candidates for use in forestation programs, considering their low susceptibility to gall wasp. The former is currently produced commercially and displays both high vigour and apical dominance, and it also has straight stems and large nuts (Miranda Fontaiña and Fernández López 2008; FernándezLópez et al. 2009); it could therefore be useful for mixed wood and nut-oriented plantations. Trees of the latter clone (not commercially produced) had a relatively high diameter and height growth and apical dominance in the field trial, so that it could be useful for plantations aimed at wood production.

The five commercial hybrid clones currently approved for use as rootstocks (' 111 ', '1483', '2671', '7521' and '7810') presented medium-to-high levels of gall wasp infestation. Nevertheless, this would not prevent their use for grafting with sweet chestnut cultivars. A similar level of susceptibility was found for 'CA-15' (non-commercial clone), which has been recommended for chestnut production because of the good nut size and early fruiting (Miranda Fontaiña and Fernández López 2008; Pereira-Lorenzo et al. 2012). Nevertheless, in these fruit-oriented plantations, the susceptibility of the clone to the pest must be taken into consideration.

Finally, it must be highlighted that climatic conditions, particularly early spring frost and summer drought, strongly limit the use of Eurasian hybrid clones in new plantations in southern Europe and in Galicia (e.g. Beccaro et al., 2020). Thus, the main limitation to growing hybrids, especially important for Eurojapanese hybrids, is their susceptibility to spring frosts due to earlier blooming; in addition, they have a higher water requirement than $C$. sativa, especially in summer months (Pereira-Lorenzo et al. 2012). As a result of these constraints, the use of hybrids is recommended for elevations lower than 400-600 m in Galicia, which corresponds almost exclusively to the coastal area of the region. For higher elevations, the European chestnut is still recommended due to its better adaptation to a wide range of environmental conditions.

\section{Conclusions}

The number of infested chestnut trees and the number of galls per tree caused by $D$. kuriphilus were not randomly spatially distributed at the local scale. Tree height was a significant predictor of both variables, suggesting that, at least at the early stage of invasion, gall wasps might use visual cues to locate suitable host trees.

Assessment of the level of infestation by chestnut gall wasp must consider concurrently different indices. We suggest the use of indices including the galls on shoots because these allow better assessment of the damage to chestnut trees. 
Our study adds to existing knowledge on the susceptibility to gall wasps of different hybrid chestnut clones and pure species. We identified two resistant hybrid clones ('110' and '334'), not previously known to be resistant, and one hybrid clone ('9187') with consistently low values for all of the indicators of infestation level. The study findings have important implications regarding selection of the plant material used in afforestation in northern Spain, where the current high rate of chestnut planting is expected to continue in the future.

Authors' contributions FCD and MJL conceived and designed the experiments. FCD, PAA and MJL performed the experiments. FCD and PAA analysed the data. BCV contributed reagents/materials/analysis tools. FCD and MJL wrote the original draft. PAA and BCV reviewed and editing the manuscript.

Funding Open Access funding provided thanks to the CRUE-CSIC agreement with Springer Nature. Funding was provided by research project AGL2016-76262-R. The funders did not participate in designing the study, data collection and analysis, decision to publish or preparation of the manuscript.

Availability of data and materials The datasets used are not publicly available but are available from the corresponding author on reasonable request.

Code availability Not applicable.

\section{Declarations}

Ethical Approval Not applicable.

Consent for Publication All authors consent to publication.

Consent to Participate All authors consent to participate.

Competing interests The authors have declared that there are no competing interests.

Open Access This article is licensed under a Creative Commons Attribution 4.0 International License, which permits use, sharing, adaptation, distribution and reproduction in any medium or format, as long as you give appropriate credit to the original author(s) and the source, provide a link to the Creative Commons licence, and indicate if changes were made. The images or other third party material in this article are included in the article's Creative Commons licence, unless indicated otherwise in a credit line to the material. If material is not included in the article's Creative Commons licence and your intended use is not permitted by statutory regulation or exceeds the permitted use, you will need to obtain permission directly from the copyright holder. To view a copy of this licence, visit http://creativecommons.org/licenses/by/4.0/.

\section{References}

Aino S (1966) Present status of forest tree breeding for resistance to insects in Asia. In: Gerhold HD, Schreiner EJ, McDermott RE, Winieski JA (eds) Breeding pest-resistant trees. Pergamon Press, Oxford Anderson SS, McCrea KD, Abrahamson WG, Hartzel LM (1989) Host genotype choice by the ball gallmaker Eurosta solidaginis (Diptera: Tephritidae). Ecology 70:1048-1054. https://doi.org/10.2307/ 1941373

Avtzis DN, Melika G, Matošević D, Coyle DR (2019) The Asian chestnut gall wasp Dryocosmus kuriphilus: a global invader and a successful case of classical biological control. J Pest Sci 92:107-115. https://doi. org/10.1007/s10340-018-1046-1 
Battisti A, Benvegnù I, Colombari F, Haack RA (2014) Invasion by the chestnut gall wasp in Italy causes significant yield loss in Castanea sativa nut production. Agric For Entomol 16:75-79. https://doi.org/ 10.1111/afe. 12036

Beccaro G, Alma A, Bounous G, Gomes-Laranjo J, Warmund M, Casey J (2020) Orchard management. In: Beccaro G, Alma A, Bounous G, Gomes-Laranjo J (eds) The chestnut handbook crop and forest management. Taylor \& Francis, pp 155-182

BOE (2020) Orden APA/1189/2020, de 2 de diciembre, por la que se dispone la inclusión de diversas variedades de distintas especies en el Registro de Variedades Comerciales. Registro de variedades. https:// www.boe.es/diario_boe/txt.php?id=BOE-A-2020-16067

Bombi P, Fedi C, Zapparoli M, Cammarano M, Guidolotti G, Pallozzi E, Gaudet M, Mattioni C, Cherubini M, Beritognolo I, Villani F (2018) Infestation potential of Dryocosmus kuriphilus Yasumatsu, 1951 (Hymenoptera: Cinipidae) in different natural populations of Castanea sativa Miller: an experimental ex situ test. Int J Pest Manag 65:147-153. https://doi.org/10.1080/09670874.2018.1483091

Bracalini M, Croci F, Turchi A, Giordani E, Tiberi R, Panzavolta T (2019) The Asian chestnut gall wasp in Italy: surveys on its native and exotic parasitoids as well as on chestnut cultivar susceptibility. Asian J Adv Agric Res 11:1-8. https://doi.org/10.9734/ajaar/2019/v11i330056

Cronin JT, Hyland K, Abrahansom G (2001) The pattern, rate, and range of within-patch movement of a stem-galling fly. Ecol Entomol 26:16-24. https://doi.org/10.1046/j.1365-2311.2001.00294.X

Díaz-Varela ER, Álvarez-Álvarez P, Roces-Díaz JV, Rodriguez-Morales B (2018) The contribution of chestnut orchard recovery projects for effective area-based conservation: two cases in Asturias (North-West Spain). In: UNU-IAS and IGES (eds) Sustainable use of biodiversity in socio-ecological production landscapes and seascapes and its contribution to effective area-based conservation. United Nations University Institute for the Advanced Study of Sustainability, Tokyo

Ding Y, Bi S, Fang G, He L (2004) Relationship between occurrence of Dryocosmus kuriphilus and development of cecidum. Ying Yong Sheng Tai Xue Bao 15:108-110 (Chinese PMID: 15139199)

Dini F, Sartor C, Botta R (2012) Detection of a hypersensitive reaction in the chestnut hybrid 'Bouche de Bétizac' infested by Dryocosmus kuriphilus Yasumatsu. Plant Physiol Biochem 60:67-73. https://doi. org/10.1016/j.plaphy.2012.07.023

DOG (2016-2021) The Official Diary of Galicia Government (DOG 120-27/06/2016; DOG 26-6/02/2019; DOG 13-18/01/2019; DOG 232-05/12/2019; DOG 17-27/01/2020; DOG 28-28/01/2021). https:// www.xunta.gal/diario-oficial-galicia/portalPublicoHome.do?fecha=20210409\&ruta=Indice66_gl.html

EFSA (2010) Risk assessment of the oriental chestnut gall wasp, Dryocosmus kuriphilus for the EU territory and identification and evaluation of risk management options. EFSA J 8:1-114. https://doi.org/10. 2903/j.efsa.2010.1619

ESRI (2015) ArcGIS® Desktop Help for Version 10.4.1, Copyright@ 1999-2015 ESRI Inc.

European Council (1999) Council Directive 1999/105/EC of 22 December 1999 on the marketing of forest reproductive material. https://eur-lex.europa.eu/legal-content/EN/ALL/?uri=CELEX\%3A31999L0105

Fernandes GW (1990) Hypersensitivity: a neglected plant resistance mechanism against insect herbivores. Environ Entomol 19:1173-1182. https://doi.org/10.1093/ee/19.5.1173

Fernández-López J (2011) Identification of the genealogy of interspecific hybrids between Castanea sativa, Castanea crenata and Castanea mollissima. For Syst 20:65-80. https://doi.org/10.5424/fs/20112 01-9136

Fernández-López J, Miranda-Fontaíña ME, Furones-Pérez P, Míguez B (2009) Clonal forestry of chestnut in Northern Spain. Centro de Investigación Ambiental (CINAM-Lourizán) Pontevedra. Xunta de Galicia. https://lourizan.xunta.gal/es/centro/departamentos/departamento-de-silvicultura-y-mejora/publi caciones

Fukuda J, Okudai S (1951) Studies on the resistance of chestnut varieties to the gall wasp (Dryocosmus kuriphilus Yasumatsu). J Appl Zool 16:147-156

Gehring E, Kast C, Kilchenmann V, Bieri K, Gehrig R, Pezzatti PB, Conedera M (2018a) Impact of the Asian Chestnut gall wasp, Dryocosmus kuriphilus (Hymenoptera, Cynipidae), on the chestnut component of honey in the Southern Swiss Alps. J Econ Entomol 111:43-52. https://doi.org/10.1093/jee/ tox 338

Gehring E, Bellosi B, Quacchia A, Conedera M (2018b) Assessing the impact of Dryocosmus kuriphilus on the chestnut tree: branch architecture matters. J Pest Sci 91:189-202. https://doi.org/10.1007/ s10340-017-0857-9

Gehring E, Bellosi B, Reynaud N, Conedera M (2020) Chestnut tree damage evolution due to Dryocosmus kuriphilus attacks. J Pest Sci 93:103-115. https://doi.org/10.1007/s10340-019-01146-0

Gençer NS, Mert C (2019) Studies on the gall characteristics of Dryocosmus kuriphilus in chestnut genotypes in Yalova and Bursa provinces of Turkey. Not Bot Horti Agrobo 47:177-182. https://doi.org/10. 15835/nbha46210906 
Geng GM, Zhu CC, Zhou JY (2015) Resistance of Castanea mollissima Shuhe-WYL strain to Dryocosmus kuriphilus and its molecular mechanism. Genet Mol Res 14:11456-11461. https://doi.org/10.4238/ 2015

Germinara GS, De Cristofaro A, Rotundo G (2011) Chemical cues for host location by the chestnut gall wasp, Dryocosmus kuriphilus. J Chem Ecol 37:49-56. https://doi.org/10.1007/s10886-010-9893-0

Gilioli G, Pasquali S, Tramontini S, Riolo F (2013) Modelling local and long-distance dispersal of invasive chestnut gall wasp in Europe. Ecol Modell 263:281-290. https://doi.org/10.1016/j.ecolmodel.2013.05. 011

Gil-Tapetado D, Castedo-Dorado F, Lombardero MJ, Martel J, Álvarez-Álvarez P (2020) Spatial propagation and patterns of abundance of Dryocosmus kuriphilus throughout an invaded region. J Appl Entomol 145:10-25. https://doi.org/10.1111/jen.12836

Gil-Tapetado D, Castedo-Dorado F, Nieves-Aldrey JL, Lombardero MJ (2021) Gall size of Dryocosmus kuriphilus limits down-regulation by native parasitoids. Biol Invasions. https://doi.org/10.1007/ s10530-020-02427-x

Graziosi I, Rieske LK (2012) Local spread of an exotic invader: using remote sensing and spatial analysis to document proliferation of the invasive Asian chestnut gall wasp. iForest 5:255-261. https://doi.org/10. 3832/ifor0633-005

Guitián J, Guitián P, Magrach A, Docampo C, Domínguez P, Guitián L (2012) Effect of management and spatial characteristics on plant species richness of Castanea sativa Mill. woodlots in the NW Iberian Peninsula. J For Res 17:98-104. https://doi.org/10.1007/s10310-011-0261-X

Guyot V, Castagneyrol B, Vialatte A, Deconchat M, Selvi F, Bussotti F, Jactel H (2015) Tree diversity limits the impact of an invasive forest pest. PLoS ONE 10:e0136469. https://doi.org/10.1371/journal.pone. 0136469

Hosmer DW, Lemeshow S (2000) Applied logistic regression, 2nd edn. Wiley, New York

Huang HH, Dane F, Norton JD (1994) Allozyme diversity in Chinese, Seguin, and American chestnut (Castanea spp.). Theor Appl Genet 88:981-985. https://doi.org/10.1007/BF00220805

Kato K, Hijii N (1993) Optimal clutch size of the chestnut gall-wasp, Dryocosmus kuriphilus Yasumatsu (Hymenoptera: Cynipidae). Popul Ecol 35:1-14. https://doi.org/10.1007/BF02515640

Kato K, Hijii N (1997) Effects of gall formation by Dryocosmus kuriphilus Yasumatsu (Hym., Cynipidae) on the growth of chestnut trees. J Appl Entomol 121:9-15. https://doi.org/10.1111/j.1439-0418.1997. tb01363.x

Kato K, Hijii N (2001) Ovipositional traits of the chestnut gall wasp, Dryocosmus kuriphilus (Hymenoptera: Cynipidae). Entomol Sci 4:295-299

Kolb TE, Fettig C, Ayres MP, Bentz BJ, Hicke JA, Mathiasen R, Stewart JE, Weed AS (2016) Observed and anticipated impacts of drought on forest insects and diseases in the United States. For Ecol Manag 380:321-334. https://doi.org/10.1016/j.foreco.2016.04.051

Kotobuki K, Mori K, Sato Y (1985) Two methods to estimate the tree damage by chestnut gall wasp Dryocosmus-kuriphilus. Bull Fruit Tree Res Stn A 2:29-36

Maltoni A, Mariotti B, Tani A (2012) Case study of a new method for the classification and analysis of Dryocosmus kuriphilus Yasumatsu damage to young chestnut sprouts. iForest 5:50-59. https://doi.org/ 10.3832/ifor0598-008

Marcolin E, Pividori M, Colombari F, Manetti MC, Pelleri F, Conedera M, Gehring E (2021) Impact of the Asian gall wasp (Dryocosmus kuriphilus) on the radial growth of the European chestnut (Castanea sativa). J Appl Ecol 00:1-13. https://doi.org/10.1111/1365-2664.13861

Míguez-Soto B, Martínez Chamorro E, Fernández López J (2018) Tolerancia a la avispa del castaño (Dryocosmus kuriphilus) en variedades tradicionales de fruto e híbridos interespecíficos. Xunta de Galicia. Centro de Investigación Forestal de Lourizán Web. https://lourizan.xunta.gal/es/transferencias/toler ancia-la-avispa-del-castano-dryocosmus-kuriphilus-en-variedades-tradicionales-de

Miranda Fontaiña ME, Fernández López MJ (2008) Caracterización de la castaña producida por los clones híbridos de castaño. Congreso Internacional de Valorización Integral do Monte. Santiago de Compostela

MITECO (2021) Registro y Catálogo Nacional de Materiales de Base. https://www.miteco.gob.es/es/biodi versidad/temas/recursos-geneticos/geneticos-forestales/rgf_catalogo_materiales_base.aspx

Murakami Y (2010) A history of studies on the chestnut gall wasp in Japan. In: Moriya S (ed) A Global serious pest of chestnut trees, Dryocosmus kuriphilus: yesterday, today and tomorrow. National Agricultural Research Center (NARO), Japan, pp 38-40

Nieves-Aldrey JL, Gil-Tapetado D, Gavira O, Boyero JR, Polidori C, Lombardero MJ, Blanco D, Rey del Castillo C, Rodríguez-Rojo P, Vela JM, Wong E (2019) Torymus sinensis Kamijo, a biocontrol agent against the invasive chestnut gall wasp Dryocosmus kuriphilus Yasumatsu in Spain: its natural 
dispersal from France and the first data on establishment after experimental releases. For Syst 28:e001. https://doi.org/10.5424/fs/2019281-14361

Nugnes F, Gualtieri L, Bonsignore CP, Parillo R, Annarumma R, Griffo R, Bernardo U (2018) Resistance of a local ecotype of Castanea sativa to Dryocosmus kuriphilus (Hymenoptera: Cynipidae) in Southern Italy. Forests 9:94. https://doi.org/10.3390/f9020094

Panzavolta T, Bracalini M, Croci F, Campani C, Bartoletti T, Miniati G, Benedettelli S, Tiberi R (2012) Asian chestnut gall wasp in Tuscany: gall characteristics, egg distribution and chestnut cultivar susceptibility. Agric For Entomol 14:139-145. https://doi.org/10.1111/j.1461-9563.2011.00551.x

Park JD, Lee SO, Park N, Ko JH (1981) Ecology and damage of Dryocosmus kuriphilus. Res Rep for Stn 28:197-205

Pereira-Lorenzo S, Ballester A, Corredoira E, Vieitez AM, Anagnostakis S, Costa R, Bounous G, Botta R, Beccaro GL, Kubisiak TL, Conedera M, Krebs P, Yamamoto T, Sawamura Y, Takada N, GomesLaranjo J, Ramos-Cabrer AM (2012) Chestnut. In: Badenes ML, Byrne DH (eds) Fruit breeding. Springer, Berlin, pp 729-770

Pereira-Lorenzo S, Costa R, Anagnostakis S, Serdar U, Yamamoto T, Saito T, Ramos-Cabrer AM, Ling Q, Barreneche T, Robin C, Botta R, Contessa C, Conedera M, Martín LM, Martín A, Gomes-Laranjo J, Villani FM, Carlson JE (2016) Interspecific hybridation of chestnut. In: Mason AS (ed) Polyploidy and hybridization for crop improvement. CRC Press, Boca Raton, pp 377-407

Pérez-Otero R, Mansilla JP (2014) El cinípido del castaño Dryocosmus kuriphilus Yasumatsu, 1951 llega a Galicia (NO de la Península Ibérica). Arquivos Entomol 12:33-36

Pérez-Otero R, Crespo D, Mansilla JP (2017) Dryocosmus kuriphilus Yasumatsu, 1951 (Hymenoptera: Cynipidae) in Galicia (NW Spain): pest dispersion, associated parasitoids and first biological control attempts. Arquivos Entomolóxicos 17:439-448

R Core Team (2020) R: a language and environment for statistical computing. R Foundation for Statistical Computing, Vienna, Austria. https://www.R-project.org/

Rodríguez-Guitián M, Rigueiro A, Real C, Blanco J, Ferreiro da Costa J (2005) El hábitat "9269 Bosques de Castanea sativa" en el extremo noroccidental ibérico: primeros datos sobre la variabilidad florística de los "soutos". Bull Soc Hist Nat Toulouse 141:75-81

Salesses G, Chapa J, Chazerans P (1993) Screening and breeding for ink disease resistance. In: Proceedings of the international congress on Chestnut, Spoleto (Italy), pp 545-549

Sartor C, Botta R, Mellano MG, Beccaro GL, Bounous G, Torello Marinonia D, Quacchia A, Alma A (2009) Evaluation of susceptibility to Dryocosmus kuriphilus Yasumatsu (Hymenoptera: Cynipidae) in Castanea sativa Miller and in hybrid cultivars. Acta Hort 815:289-298. https://doi.org/10.17660/ ActaHortic.2009.815.38

Sartor C, Dini F, Torello Marinoni D, Mellano MG, Beccaro GL, Alma A, Quacchia A, Botta R (2015) Impact of the Asian wasp Dryocosmus kuriphilus (Yasumatsu) on cultivated chestnut: yield loss and cultivar susceptibility. Sci Hortic 197:454-460. https://doi.org/10.1016/j.scienta.2015.10.004

Shiraga T (1948) Studies on the gall of chestnut. J Okayama Agric Exp Sta

Stone GN, Schonrogge K, Atkinson RJ, Bellido D, Pujade-Villar J (2002) The population biology of oak gall wasps (Hymenoptera: Cynipidae). Annu Rev Entomol 47:633-668. https://doi.org/10.1146/annur ev.ento.47.091201.145247

Vieira da Costa F (2011) Relationship between plant development, tannin concentration and insects associated with Copaifera langsdorffi (Fabaceae). Arthropod-Plant Interact 5:9-18. https://doi.org/10.1007/ s11829-010-9111-6

Xunta de Galicia (2018) 1ª revisión del Plan Forestal de Galicia. Consellería do Medio Rural, Xunta de Galicia. https://mediorural.xunta.gal/sites/default/files/temas/forestal/plan-forestal/1_REVISION_ PLAN_FORESTAL_CAST.pdf

Xunta de Galicia (2020) Estadísticas Forestales. Consellería do Medio Rural, Xunta de Galicia. https:// mediorural.xunta.gal/es/recursos/estadisticas/estadisticas-forestales

Publisher's Note Springer Nature remains neutral with regard to jurisdictional claims in published maps and institutional affiliations. 


\section{Authors and Affiliations}

\section{Fernando Castedo-Dorado ${ }^{1}$ (D) Pedro Álvarez-Álvarez ${ }^{2}$ (D) Beatriz Cuenca Valera $^{3}$. María Josefa Lombardero ${ }^{4}$ (D)}

Pedro Álvarez-Álvarez

alvarezpedro@uniovi.es

Beatriz Cuenca Valera

bcuenca@tragsa.es

María Josefa Lombardero

mariajosefa.lombardero@usc.es

1 Grupo de Investigación GEOINCA, Universidad de León, Campus de Ponferrada. Avda. de Astorga s/n., 24401 Ponferrada, Spain

2 Departamento de Biología de Organismos y Sistemas, Universidad de Oviedo, C/ Gonzalo Gutiérrez de Quirós s/n, 33600 Mieres, Asturias, Spain

3 Departamento de Mejora Agroforestal, TRAGSA, Ctra de Maceda-Valdrey km 2, 32700 Maceda, Ourense, Spain

4 Unidad de Gestión Ambiental y Forestal Sostenible, Universidade de Santiago de Compostela, Campus Universitario s/n, 27002 Lugo, Spain 